\title{
A Sustainable Approach for a Smart Human Resource Management in Healthcare
}

\author{
Hubertus Franke ${ }^{1}$, Martina Hasseler ${ }^{2}$, Denise Dick ${ }^{3}$, Stephanie Krebs ${ }^{3}$
}

\begin{abstract}
Sustainable healthcare only works with sufficient and high performance employees for all specialized areas. Especially in nursing care more and more employees are needed because of the demographic factor and the shortage of nurses. Furthermore, it needs to take into account that there are nurses, who are still willing to work in this job but have special requirements to the working conditions, e.g. working without night shift or only to special times. One possibility to optimize this scenario is employing job-hoppers in nursing. Another one is founding a regional hospital network. Different clinics, which are located in the same area, establish a joint venture. This joint venture use smart information-technology-support to hire nurses on various and specific requirements. Also, it will be possible for the hospitals to request more staff to fill in gaps of working schedules. The challenge is, to manage all constraints of the corresponding hospitals, e.g. the different processes and the different data-structures. This publication focuses on description of a hospital-network, the processes and the required software.
\end{abstract}

\section{Keywords: Hospital network, sustainable healthcare, nursing pool}

\section{Introduction - The Problem of Vacant Jobs in Healthcare}

A very important area of environmental sustainability can be observed in healthcare and nursing care. As often discussed in media, there is a big problem finding qualified employees for healthcare in Germany. Sustainable healthcare only works with sufficient and high performance employees for all specialized areas. Especially the nursing care needs more and more employees because of the demographic factor and the shortage of nurses. On the one hand a lot of older nurses will retire while on the other hand there are only a few younger people left to work in the healthcare sector (Nanninga, 2014). Furthermore, the number of patients increases (Grieß, 2015), (Nowossadeck, 2013). Consequentially, a decreasing number of employees will take care of an increasing number of patients for 365 days a year in shift work. But hospitals have to be staffed with sufficient qualified personnel to guarantee high quality care for patients (Aiken et al., 2011), (Butler, 2011), (Aiken et al., 2014). According to this, it is inevitable discussing the shortage of nursing staff causes strategic assurances as well as effectively and efficient coordination of employees in hospitals (Damart \& Kletz , 2016). Therefore, there are many small regional hospitals experiencing big problems to fulfil all requirements of patients already (Deller, 2009).

In addition, in compliance with statutory regulations it is very difficult to fill up gaps in personnel time scheduling with employees of own ranks (Weskamm, 2016). Also, hospitals use job-hoppers to optimize the situation, it do not led to any relief caused by a

\footnotetext{
${ }^{1}$ Professor at Ostfalia.- University of Applied Sciences, Germany

2Professor at University of Heidelberg, Germany

${ }^{3} \mathrm{PhD}$ Student at Ostfalia.- University of Applied Sciences, Germany
} 
poor coordinating structure (Benedix \& Medjedovic', 2014). Furthermore, the poolconcept, which is known in Germany and hospitals of other countries for example as "Bank Nurse-Concept" to solve staff shortages, is very time-consuming so far. Staff members of the personnel department or head nurses have to take many calls until they get a suitable replacement (Damart \& Kletz , 2016). Moreover, different software tools for time planning support exist. However, these planning tools are not able to fix the problem of staff shortage either (Benedix \& Medjedovic', 2014). Facing the increasing complexity, this cannot be handled by manual methods anymore.

The shortage of specialist and nurses in healthcare will grow on during the next years. As per

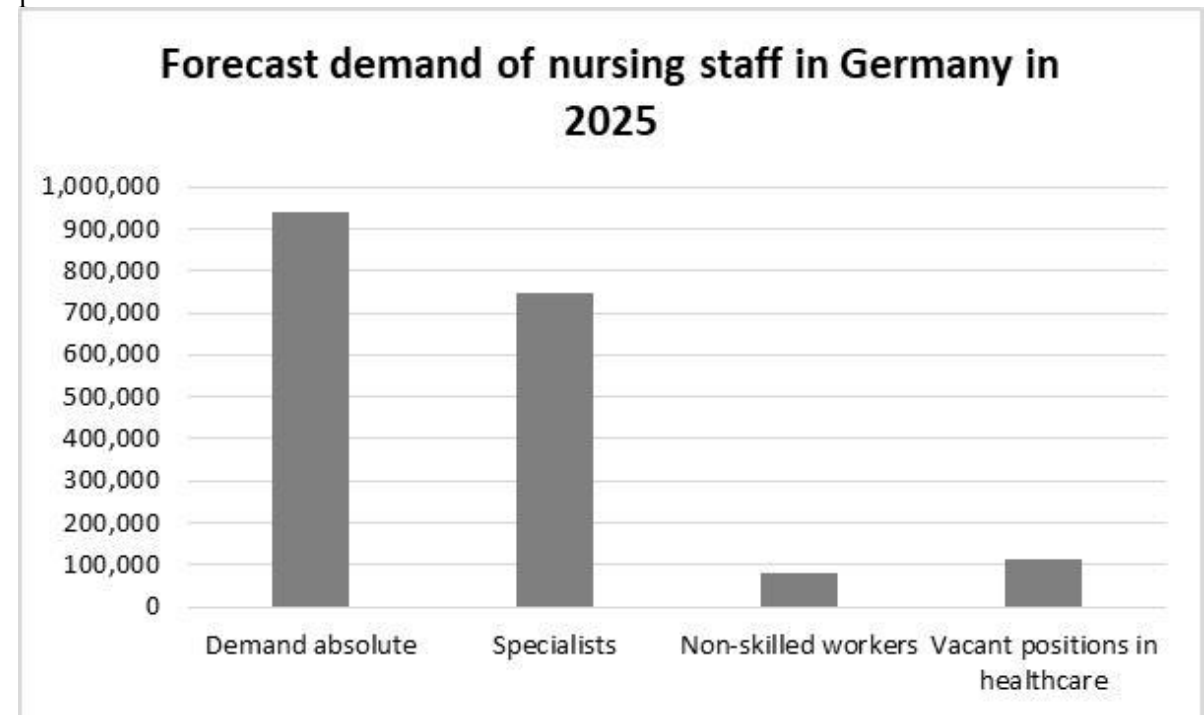

Figure 1, a forecasted demand in healthcare forced nearly 1 million employees until 2025.

In detail, up to 747,000 specialists in healthcare will be needed. In spite of the possibility deploying 81,000 employees without any professional training, there will be a difference about 112,000 vacant positions left (Becker, 2017), (hu Versicherungen, 2018). 


\section{Forecast demand of nursing staff in Germany in 2025}

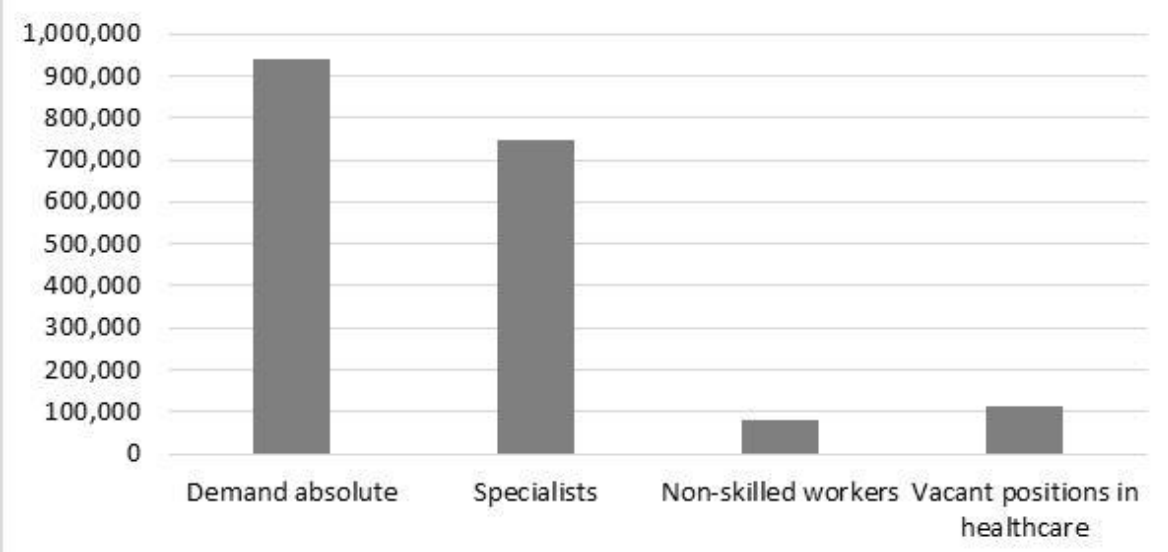

Figure 1: Demand of specialist in healthcare in Germany in 2025 (SZ. (n.d.)., 2018)

In addition, an actual survey related of "tagesschau September 21, 2017" indicates a gap of 350,000 specialists in healthcare in 2030 (Deutscher Pflegerat, 2017). Furthermore publications, media and $66 \%$ of coordinators of intern hopper-programs, who were interviewed in this project, point out that there are nurses who are still willing to work in their job but have special requirements to the working conditions, e.g. working without night shift or working only to special times, firmly scheduled working hours (prosoftTeam, 2017) . To find a new, flexible and structured solution for the described problem, it is necessary to analyse the Human Resource Management, especially the process of staff acquisition and distribution in healthcare, in more detail (Butler, 2011).

\section{Basics of Staff Acquisition in Healthcare}

The staff acquisition in healthcare can be considered from two different points of view. The first one is, hiring nurses generally for one hospital or nursing home. Hospitals handle this in conventional way so far. Candidates apply for a special position in a hospital or in nursing homes via internet or in paper based manner. At the best an applicant fulfils the requirements and the hospital hire him or her immediately. Because of a small number of applications this approach is in current situation rarely successful. Hence, some hospitals pay very high provisions to find new employees (Straßmann, 2014). Especially employment agencies use this for making big profit (Thelen, 2018).

The other requirement of acquisition manpower in healthcare is filling in gaps in personnel time schedules. Caused by illness or other short-term absences of staff members, head nurses or employees of the personnel department have to take several calls until they get suitable replacements. In many cases this process is very timeconsuming so far. Furthermore, it is discontentedness for the person calling as well as for the nurses being called. Very often nurses, who have some days off or are on holiday, have to come in (Damart \& Kletz , 2016). Beyond that, not all nurses in time off have 
the right skills or may help filling in the time schedule gap. Moreover, there are lots of laws and rules regulating the work in the healthcare sector in Germany. For example it is not allowed to work one day in night shift and the day after in a morning or afternoon shift. It is also mandatory having at least 15 free Sundays within a year (Bundesministerium für Arbeit und Soziales, 2017).

Depending on these problems, some smaller hospitals in countryside enter into a cooperation agreement with some other hospitals in the surrounding area to share staff members (Deller, 2009). Based on this, it is a promising approach founding a synergetic cooperation between existing institutions in healthcare. The idea of the project, which will be described in the following, is to establish a joint venture based on a smart IT-tool between three different hospitals located in the same geographic area. This joint venture will work like a "temporary employment agency" for the specific kind of hospital network and will be capable to react quickly and flexibly on demand.

The described idea, with high innovation potential through process and organizational innovation, is comparable to the industrial resource management, where numerous studies and developments have created advantages for Industry and Logistic already. Applied logistic is using IT-tools and further IT-based support to handle very big packages of data (Franke \& Matteoschat, 2009), (Franke, 2013), (Franke, 2014). The idea is, to transfer this approach to the Human Resource Management in hospitals.

But for using the IT-tool in a hospital network of three hospitals in competition with each other, the idea of the described project is assuming an organization development as well. One big challenge is to manage all constraints of the corresponding hospitals, e.g. the different processes and the different data-structures. Another challenge is to get them working together on this project by sharing and discussing their demand (Deller, 2009).

\section{Basics of Hospital Networks}

In a hospital network every hospital works along their own processes, rules and standards. Nevertheless, there are lot of standards given by the government; the amount of individual processes is enormous. To build up a hospital network, respectively a joint venture as an economical supply chain, standardization in processes, standards in the pay scale (the rate) and especially in IT-infrastructure are needed. Thus, a staff time scheduling must have the same data structure in every corresponding hospital in the network. Furthermore, it is indispensable that the employee and executives of every hospital go along with the new idea and implementation of new processes and rules (Deller, 2009).

\section{A Regional Hospital Network for a Synergetic Exchange of Employees in Healthcare}

Especially for the lack of specialists in the social economy in Germany this research approach designs a concept with quick respond. Due to strategic assurance and a more adapted catalogue of measures this project works together with three different hospitals, which are integrated in a regional network of politics, economic and sciences already to activate regional available recourses, potentials and manpower. Therefore, one economic partner of the regional network is integrated. The project is subsidized by 
Funds from the European Regional Development Fund (according to the directive about grants for innovation networks).

Figure 2 and Figure 3 show that the project is divided into two phases with twelve different working packages (WP), six in each project phase. In the first project phase, the researchers analyse framework, processes and requirements for an IT-based Human Resource Management tool. To find out more about the attitudes and perspectives from hospital staff and management, the researchers use group interviews of nurses to ask them about the ideal conditions and requirements of the smart IT-tool and hospital network in WP 1. To ask about ideas and suggestions for the smart IT-tool of hospital management as well, they do lead guided expert interviews with decision-makers of the three hospitals in WP 4. In addition, they use the qualitative content analyses of Mayring to accumulate the group and expert interviews to a specification sheet (Mayring, 2010).

Subsequently, in WP 2 is developed the legal prerequisites, to secure that the software will be allowed to insert in different hospitals on employment law and data protection. Therefor the law department of Ostfalia University of applied sciences and the experts about law of the three hospitals do a literature search and analysis.

In WP 3 the scientists carry out a modelling and state analysing of the current processes of filling in gaps in time scheduling. In addition, they closely monitor weak points of all current processes. To simplify, the weak points are evaluated and priorities varies focused on distribution of Human Resources. Based on this, they design a target process by using Petri-nets modelling.

In WP 5 the academics starts the software modelling by an initial prototyping of the smart software to get to know some challenges from this perspective as well. The first project phase ends in WP 6 by a workshop of all involved to discuss the results of this phase.

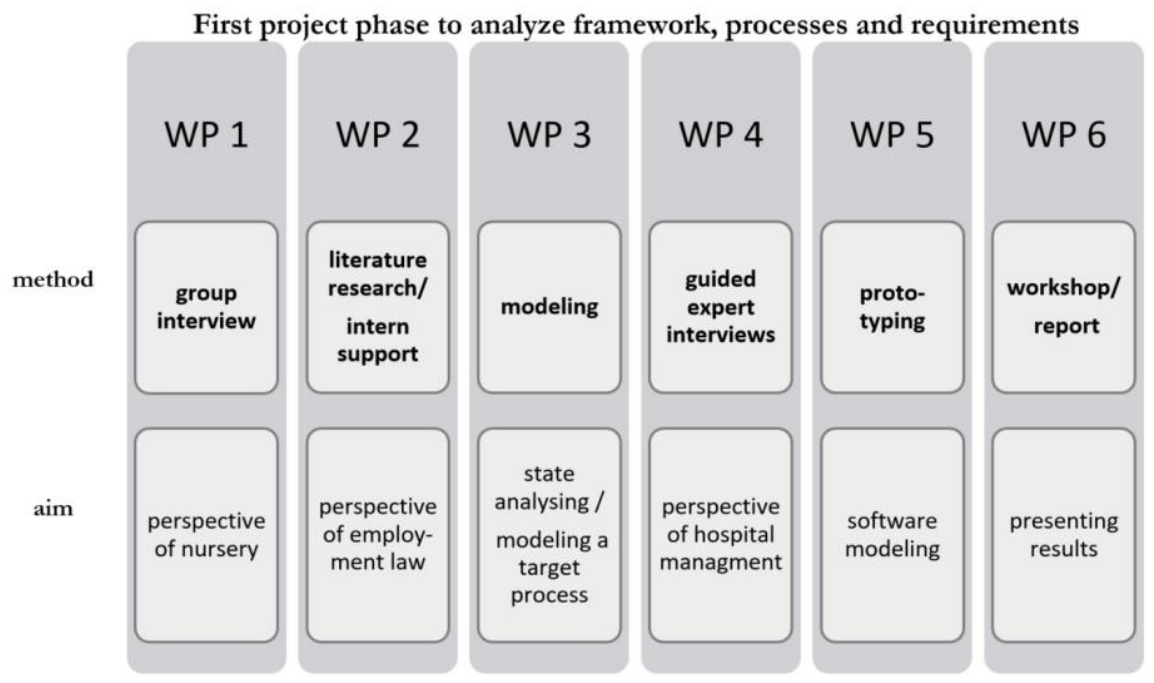

Figure 2. First project phase - HNET 1

After researching the framework for a joint venture of a hospital network bases on a smart IT-tool in the first project phase, it is possible to install the software prototype in each of the cooperating hospitals in a scenario, which is close to reality and examined in 
feasibility and effectiveness, in the second project phase.

In WP 1 of the second project phase the researchers define criteria like workability of the program, understanding of the instrument, fulfilment of the requirements of responsible person's view, efficient use of personnel, effective use of personnel, satisfaction of the involved nursing directorates, satisfaction of the head nurse and many more as evaluation criteria.

Based on these, they specify data collection tools for example guidelines for interviews, online questionnaires or guidelines for joining observations in WP 2 to get feedback of the employed nursing staff, responsible personnel manager, nursing directorate or nursing management about using the prototype software.

In WP 3 the results of the different WP's from project phase one are used to enforce a "second" software prototyping. It portrays the feasibility of the actual real implementation and suggests an optimized distribution of hospital staff, based on all important data. Modifications of the prototype are always possible and requested because a "Rapid Prototype" is used. The researchers use a tool-supported approach, because numerous software components from the large area of IT-based project management are already available.

Against the background, training leads to motivated using and testing, the scholars design workshops and seminars to instruct all responsible persons (personnel managers, nursing service management and personnel manager) of the three hospitals to use the smart software tool effectively during their working day in WP 4.

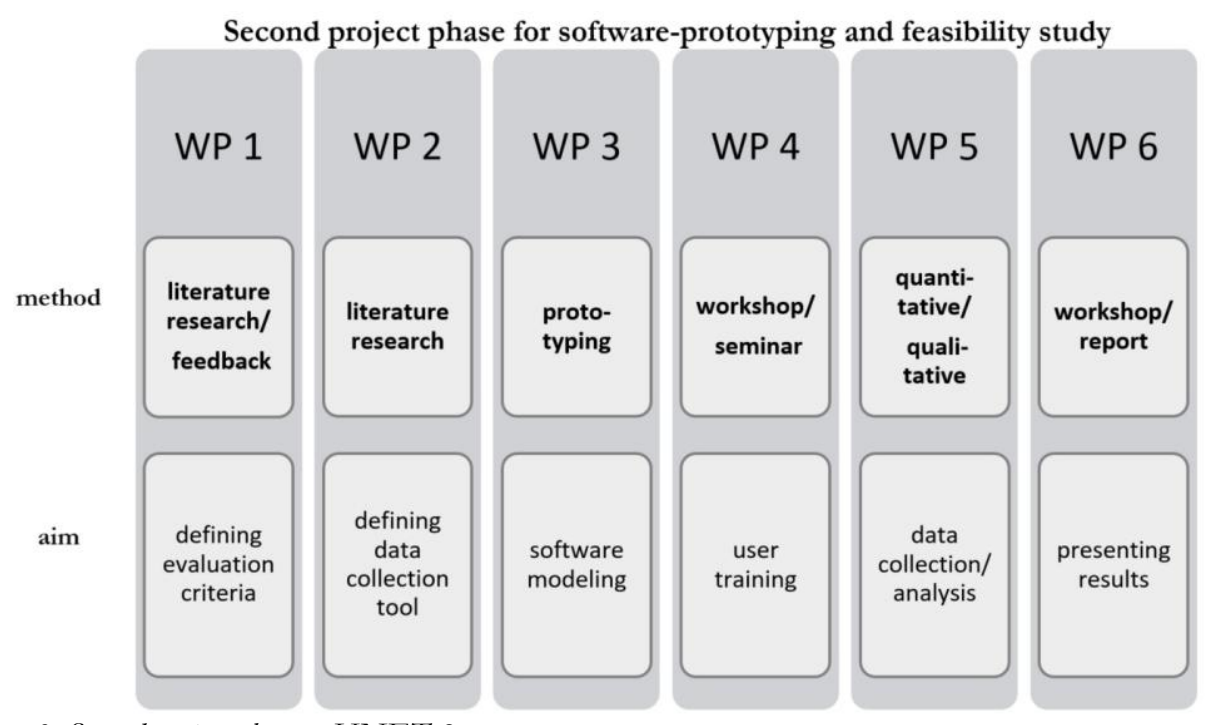

Figure 3: Second project phase - HNET 2

In case of this, it is possible to collect various data about using and handling the software along the designed data collection tools of WP $1+2$ in WP 5. Beside of this, the researchers analyse these results and adapt them to the prototype, whenever it is required. Also they tests prototypical created software for special parts of different hospitals. Though, they check the created prototype for all necessary requirements. In case of this the prototype must bases on up-to-date programming language, commonly 
available on the free market (e.g. Java or similar object-oriented programming languages). At the end of the second project phase all results are presented in a workshop to the involved partners in WP 6 as well. Furthermore, a foundation of the pooling company is needed. Thereby it is necessary, that the new joint venture is only responsible for hiring pool employees to fill in gaps in time schedules. This should be done parallel to the conventional way for hiring new employees for special vacant positions in one clinic of the hospital network.

\section{IT Framework}

As described above the IT framework is one of the main factors to create a flexible and quick solution to find suitable replacements in gaps within time schedules. In case of this, the idea of modeling smart software will be described in more detail in this chapter.

The first step, filling in a time schedule gap, consists primarily on generating a list with all eligible nurses. And exactly this is the biggest challenge. Beside the laws and rules regulating a working day, there is no standard procedure to generate the list and the algorithm behind this process may change according to the problem (short or long-term gap, special skills need, gap on a working day or weekend, etc.). Anyhow, there is a way to reproduce these procedures in software.

Although the process finding a substitute nurse may differ among the hospitals, they all aim the same goal: reallocating nurses as efficient as possible to fill in the gaps in a running time schedule.

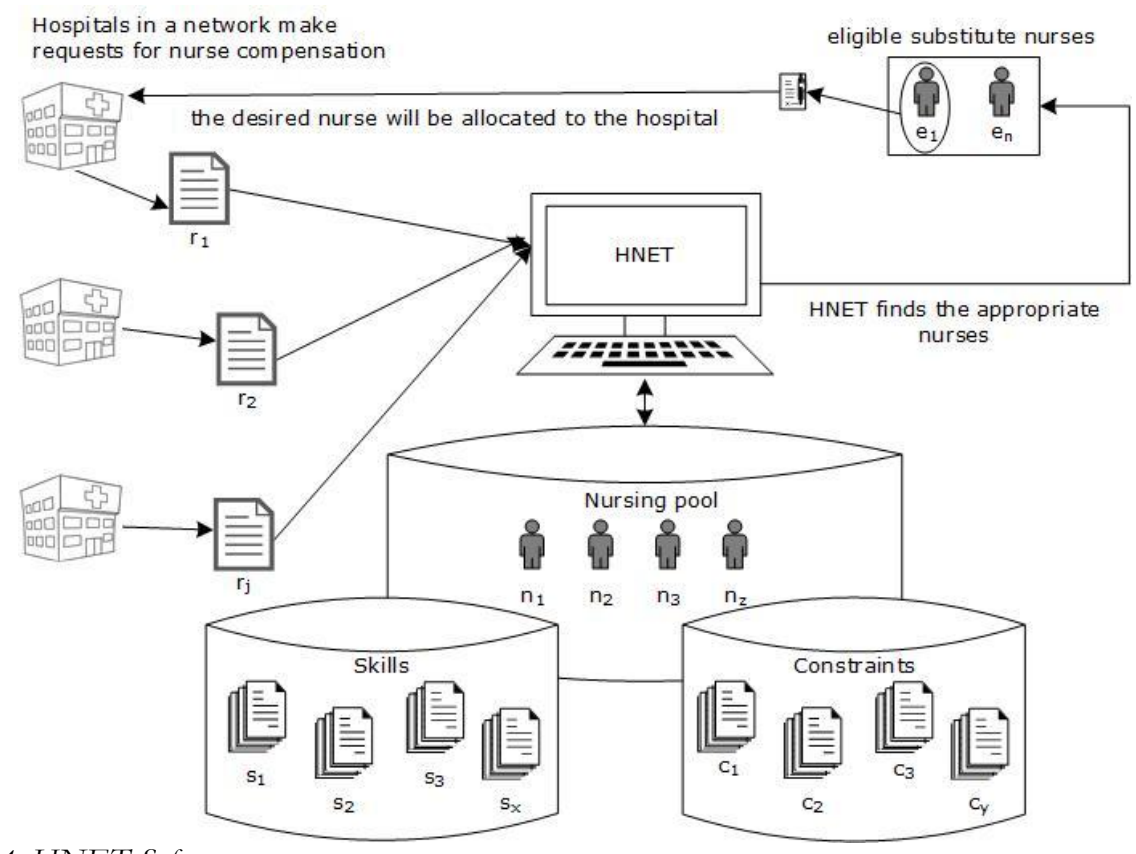

Figure 4: HNET Software

The Hospital Network (HNET) Project aims supporting the hospitals filling in the gaps 
as efficient and effective as possible. Therefore, a web based software prototype will be developed. In this, hospitals in a regional network will be able to make requests for nursing compensation. At least each request contains the skills and the period the substitute will be needed for. Based on this information, a list with all eligible substitute nurses will be generated and provided to the specific hospital, which decides who they want to recruit. Against the actual process, this person will automatically contacted by a short message. In case of a positive answer, the nurse will be allocated to the hospital and blocked for all other requests within the booked period (Figure 4).

Anew against the actual system, the nurses being contacted are not in time off. When they register for the nursing pool, they are able to set their constraints (e.g. the cities, the days and time they are capable to work). The HNET-Software is just going to match requests that attend these restrictions.

The HNET-Software consists of a database with nurse information (e.g. skills and constraints) as well as a database with the requests and all information related to them (Figure 4). For each request, nurse's and request's information will be matched generating a list with the eligible substitute nurses. Therefore:

Let $\boldsymbol{N}$ be a set of nurses in the nursing pool, where $N=\left\{n_{1}, n_{2}, \ldots, n_{z}\right\} \wedge|N|=z$

Let $\boldsymbol{S}$ be a set of nurses' skills, where $S=\left\{s_{1}, s_{2}, \ldots, s_{x}\right\} \wedge|S|=x$

Let $\boldsymbol{C}$ be a set of nurses' constraints about labour, where $C=\left\{c_{1}, c_{2}, \ldots, c_{y}\right\} \wedge|C|=y$

Let $\boldsymbol{R}$ be a set of requests for a substitute nurse, where $R=\left\{r_{1}, r_{2}, \ldots, r_{j}\right\} \wedge|R|=j$

Let $\boldsymbol{E}$ be a set of eligible nurses, where $E=\left\{e_{1}, e_{2}, \ldots, e_{n}\right\} \wedge|E|=n$

After all matches were found and weighted, the list with the eligible nurses is generated and offered to the hospital for further evaluation. The requests themselves are divided in three possible categories: proactive, reactive recommendation and reactive request.

Proactive: the easiest way for the hospitals to find substitute nurses is uploading a time schedule to the HNET web application. The software will automatically interpret it. Once vacant positions are recognized, the software will be able to match the requirements to the skills and constraints of the nurses in the nursing pool generating a list with eligible substitutes. The list will be delivered to the hospital, which hires one or more of the suggested nurses in case of demand

Reactive recommendation: like the "proactive" solution, the hospitals are able to upload time schedules to the HNET web application. In this case the time schedules will only be interpreted and the list with the eligible substitutes will only be generated after the application has been triggered to do it.

Reactive request: this solution offers the most interaction with the user, a hospital in this case. A list with eligible substitute nurses can only be generated after the user has filled in a web based form, providing all essentially information (e.g. the exact days, shifts and skills needed for the open position).

The first two categories implicate the interaction between HNET-Software and the time schedule software of the hospitals. Various hospitals may use different software, so an extra inter layer will be needed interpreting the time schedule and deleting all nonrelevant and individual-related information.

Independent of the request model used by the hospital, all them helps improving the 
efficiency - labour as well as organizational - and helps managing the difficult and timeconsuming problem of finding a substitute nurse for a free time-slot. Furthermore, it also helps solving the dissatisfaction of the employees because the regular staff will not be called, while being in time off.

\section{Implications}

The described project approach shows that cross-sectoral cooperation and networks are very useful to meet challenges in effective operations. Synergy effects, for example knowledge, financial aspects and manpower, lead to very effective solutions for every project partner. Mainly caused by increasing competitive pressure and absence of specialization, there are rare hospital networks in Germany yet (Deller, 2009). Therefore, the described project demonstrate that ideas transferred from industry can be used in social institutes and healthcare in very good manner. Analysing and optimizing a big data process, by developing an IT-based tool for support, will lead to more effectiveness and efficiency in social area as well. This is very important to reduce the pressure of the employees in hospitals. Moreover, simple and transparent processes raise motivation and employee satisfaction. These are two main facts to make employees stay for work in healthcare.

\section{Summary}

The publication focuses the description of a project approach to analyse requirements, processes, modelling and usability of IT-based Human Resource Management software in healthcare. A hospital network of three hospitals, plus support of a smart IT-tool, is one possibility to counteract the effects of the growing shortage of nurses by coordinating the available resources targeted on demand to time and place. On the one hand, this is needed in case of a shortage of nurses based on demographic factors. On the other hand, working conditions and salary are not attractive enough for employees working in hospitals anymore. Hence, many nurses do occupational changes to temporary employment agencies or other jobs. This has negative impact to the quality of patient care in hospitals. Therefore, hospitals search several ways of getting nurses back, working as hospital nurses. The described project bases on Funds from the European Regional Development Fund and operates on an innovative idea to sensitize hospitals for positive effects of a hospital network and the employment of modern IT systems. Rest on this, the idea led to an intern temporary employment agency bases on IT support. This joint venture of hospitals may hire employees, who will only work for these special hospitals of the specific network. In case of this, the hopper-nurses will get to know the processes and characteristics of the special hospitals very quick. After a training they will be able to work flexible but on high quality in each of these hospitals. Caused on recurring cooperation, the hopper-nurse of the joint venture and the hospital nurses will get to know each other and learn to work in an efficient team without any extern-intern barriers. The joint venture should be seen as a parallel solution to hire nurses in one hospital of the network. 


\section{References}

Aiken et al., L. (2011). Effects of Nursing Staffing and Nurses Education on Patient Deaths in Hospitals With Different Nurse Work Environments. Medical Care 49.

Aiken et al., L. (2014). Nurse staffing and education and hospital mortality in nine European Countries: a retrospective observation study. The Lancet.

Becker, K. B. (2017, 04 21). Pflege in Deutschland -Wie die Digitalisierung dem Fachkräftemangel begegnet. Süddeutsche Zeitung, München Seit 16, Bayer Seite 16.

Benedix, U., \& Medjedovic, R. (2014). Gute Arbeit und Strukturwandel in der Pflege: Gestaltungsoptionen aus Sicht der Beschäftigten (Vol. Reihe Arbeit und Wirtschaft in Bremen). (I. A. (IAW), Ed.) Bremen: Institut Arbeit und Wirtschaft (IAW) .

Bundesministerium für Arbeit und Soziales. (2017). Arbeitszeitgesetæ: Retrieved from http://www.bmas.de

Butler, M. (2011). Hospital nurse staffing models and staff-related outcomes. Cochrane Database Syst Rev 6.

Damart, S., \& Kletz , S. (2016, 01). When the management of nurse absenteeism becomes a cause of absenteeism: a study based on a comparison of two health care facilities. Journal of Nursing Management, pp. 24:4-11.

Deller, U. (2009). Kooperationsmanagment. Ein Lehr- und Arbeitsbuch für Sozial-und Gesundheitsdienste. Opladen \& Farmington Hills: Verlag Barbara Budrich.

Deutscher Pflegerat. (2017, 01). deutscher-pflegerat.de. (D. P.-u. Hebammenwesen, Ed.) Retrieved 06 18, 2018 , from deutscher-pflegerat.de: https://deutscher-pflegerat.de/aktuelles/newsletter/DPR_Newsletter_01_-Januar_2017.pdf?m=1483968541\&

Franke, H. (2013). Multiagentensimulation in komplexen Logistiksystemen am Beispiel der der Baustellenlogistik. ASIM Fachtagung Simulation in Produktion und Logistik. Fürstenalle 11, 33103 Paderborn.

Franke, H. (2014). Agent based environments using Petri-Net-Profiles in constructing sites. 2rd Annual International Conference on Industrial, Systems and Design Engineering. Athens, Greece.

Franke, H., \& Matteoschat, S. (2009). Dezentrale Produktionsablaufplanung mittels Agentensimulation. 11. Paderborner Frübjabrstagung - Nachbaltiggkeit im flexiblen Produktions- und Liefernetzwerken. Fürstenallee 11, 33103 Paderborn.

Grieß, A. (2015, 09 17). Spiegel ONLINE. Retrieved 06 12, 2018, from Spiegel ONLINE: http://www.spiegel.de/gesundheit/diagnose/krankenhaus-statistik-weniger-kliniken-mehrpatienten-a-1053286.html

hu Versicherungen. (2018, 06 18). Pflegeversicherung-direkt.de. Retrieved from Pflegeversicherung-direkt.de: https://www.pflegeversicherung-direkt.de/service/pflege-in-zahlen.html

König, J., \& Raiß, M. (2015). Dienstplangestaltung - was Pflegekeräfte wissen müssen. Ein Ratgeber für die tägliche Praxis. Hannover: Schlütersche (Pfllege-Kolleg).

Mayring, P. (2010). Qualitative Inhaltsanalyse. In G. Mey, \& K. Mruck, Handbuch Qualitative Forschung in der Psychologie. Verlag für Sozialwissenschaften.

Nanninga, J. (2014). Fachkräftemangel in der Pflege. Darstellung eines Imagekonzepts, Personalbindungsstrategien und Maßnahmen zur Nachwuchsrekrutieruntg. Hamburg: Diplomica Verlag.

Nowossadeck, S. (2013, 08). Demographic change, people needing long-term care, and the future need for carers. An overview. Bundesgesundheitsblatt Gesundheitsforschung Gesundheitsscbut:

prosoft-Team. (2017, 10 18). hr-blog.prosoft.net. Retrieved 06 18, 2018, from hr-blog.prosoft.net: https://hrblog.prosoft.net/zeitarbeit-fuer-pflegekraefte/

Straßmann, B. (2014, 03 13). Pflegekräfte: Schluss mit Schwester! Die Zeit (12).

SZ. (n.d.). (2018, 06 20). Prognostizierter Bedarf an Pflegekeäften* in Deutschland im Jahr 2025. Retrieved from Statista: pflegekraeften-2025/

Thelen, P. (2018, 04 03). Konkurrenz im Altenheim. Wie Leiharbeitsfirmen den Markt für Pflegekräfte aufmischen. Handelsblatt, https://www.zeit.de/2014/12/kopfgeld-pflegepersonal-klinik.

Weskamm, A. (2016). Dienstplanung im Krankenhaus. (D. B. (DBfK), Ed.) Mein Recht auf Freil, Sammelband zur DBfK-Aktion, 6. 